\title{
ANTHROPOMETRIC MEASUREMENTS OF THE BODY COMPOSITION OF CANCER PATIENTS DETERMINE THE PRECISE ROLE OF THE BODY SURFACE AREA AND THE CALCULATION OF THE DOSE OF CHEMOTHERAPY
}

\author{
AIJA GERINA-BERZINA ${ }^{1}$, ULDIS VIKMANIS ${ }^{1}$, \\ ULDIS TEIBE ${ }^{2}$, SILVIJA UMBRASHKO ${ }^{2}$ \\ ${ }^{1}$ Faculty of Medicine, University of Latvia \\ ${ }^{2}$ Department of Anatomy and Anthropology, Riga Stradinš University, Latvia
}

\begin{abstract}
The calculation of an accurate dose of chemotherapy for oncological patients reduces the possible medication errors and the toxicity of the body and so it improves the outcome of the treatment (survival). In oncological practice for the calculation of the dose of chemotherapy the human body surface area (BSA) is used. The human body surface area is determined by derived formulas, but it is not directly linked to the pharmacokinetics of the drugs. Pharmacokinetic studies have demonstrated that for the calculation of the chemotherapy dose the actual body weight should be taken into account rather than the ideal one. In the therapeutic dose determination the body fat mass has essential significance.

202 patients aged from 19 to 83 years with various tumor localizations underwent anthropometric measurements (height, weight, circumferences, fatfold thickness, the distance between the hills above the joint), the body mass index (BMI) and the BSA (according to the Mosteller formula).

The average weight of 99 men was $78.5 \pm 16.4 \mathrm{~kg}$ and the mean body weight of 103 women was $70.1 \pm 14.6 \mathrm{~kg}$, statistically non-significantly different $(\mathrm{F}=0.358, \mathrm{p}=0.551)$, but the independent-sample $\mathrm{t}$-test arithmetical mean differed statistically significantly $(\mathrm{t}=3.839, \mathrm{p}<0.001)$. The oncological patients
\end{abstract}


in the absolute and relative distribution of groups according to the body mass index in relation to the patients gender differed statistically significantly $\left(\chi^{2}=\right.$ $11.510, \mathrm{df}=4, \mathrm{p}=0.021$ ). Half of the men had ideal weight (body mass), but only about $1 / 3$ of women were with the ideal body weight. The men's average body mass index was $25.41 \pm 4.73 \mathrm{~kg} / \mathrm{m}^{2}$ and the women's average body mass index was $26.20 \pm 5.90 \mathrm{~kg} / \mathrm{m}^{2}$. After arithmetic calculation of the body surface area using a variety of formulas, men's BSA differs less than $1 \%$ compared to the calculated area of Mosteller formula. For women the differences are more than $1 \%$. Distribution of patients in groups body fat content (\%) of the patient's shows that male and female patients were primarily from the group with excessive fat in the body, the body fat for men is $25 \%$ or more of the total body weight, but for the women it is over $32 \%$ of the total body weight. Correlation analysis showed that the body fat for men correlates with the body surface area, calculated using the Mosteller formula $(r=0.663, p<0.001)$ and the fat content for women correlates with the body surface area, calculated using the Mosteller formula $(\mathrm{r}=0.760, \mathrm{p}<0.001)$. The male body volume of the mean value was $75,0 \pm 17.1 \mathrm{dm}^{3}$, the female body volume of the mean value was 68 , $6 \pm 15.6 \mathrm{dm}^{3}$. After the independent samples t-test between men and women in body volume arithmetical means differed statistically significantly $(t=2.437$, $\mathrm{p}=0.016)$.

Anthropometric measurements are suitable for the calculation of the doses of chemotherapy, but taking into account the correlation, it cannot be excluded that they reflect the same body surface area. The BMI does not feature the percentage of the fat mass of the whole body. Consequently, it is possible that the patient's body density is a more physiological parameter, which could be determined for comparison by using abdominal computer tomography. The body volume index(BVI) could be one of the most recent parameters for the more accurate calculation of chemotherapy for cancer patients. The Body Volume Index (BVI) is a new measurement for human obesity that has been proposed as an alternative to the Body Mass Index (BMI).

Key words: body surface area (BSA), chemotherapy, body mass index (BMI), body volume index(BVI)

\section{INTRODUCTION}

Individuals' response to receiving chemotherapy can be very different, with significant clinical implications. A successful chemotherapy program develops a consistent therapeutic effect minimizing normal tissue toxicity. A fixed-dose chemotherapy reduces the calculation of potential medication errors [6]. 
Chemotherapy dose calculation is using the human body surface area(BSA). For the BSA calculation different derived formulas are used. The means of the measurement of patients of different ages, shapes and sizes a formula for calculating the surface area using weight and height was first derived in 1916(DuBois and DuBois) [4]. The surface area has been defined by a concept, that it is variable with difficult reproductive assessments. Currently, several institutions are using the $\mathrm{Du}$ Bois formula. There are several arguments for and against the Du Bois formula used to calculate body surface area. The fact that the nine subjects who were assessed had different body shapes is in favor of the $\mathrm{Du}$ Bois formula. However, many researchers have questioned the accuracy of the formula. In the results of the study, Jones and his colleagues [10] have shown that this equation is not the most accurate, because the $\mathrm{Du}$ Bois and Du Bois formula estimate only one leg and arm assuming that the body is symmetrical. But this assumption cannot be applied to people with disabilities [2], as well as the formula greatly overestimates the surface area of the people who are overweight (obese). The above-described results were supported by Wand and his colleagues in 1992. Since the Du Bois formula was derived from a small number of individual measurements, where some of them had skeletal deformities and only one child was included, the question of the reasonableness and accuracy of the formula for babies, people with excess body (pregnancy, obesity, high height) was raised. The Du Bois formula accuracy was evaluated using the predictive mean squared error (RMSE interpreters. Vkk) method. RMSE is the degree of correlation between the measured and the expected data because the $\mathrm{Du}$ Bois formula systematically underestimates the BSA (body surface area) by almost 5\%. After the RMSE methods there are about 15 different formulas to predict the BSA, 8 is the RMSE of less than $8 \%$. The $\mathrm{Du}$ Bois formula ranks fifth on the lowest RMSE. Nevertheless, the Du Bois formula continues to be used, probably more than a tradition of precision and for most drug manufacturers still provide its customers with nomograms, which is taken as the basis for this formula. Nomograms are printed in the standard text, which does not always accurately reproduce the original, which increases the risk to underestimate the surface area. A change in the BSA from 1.87 to $1.60 \mathrm{~m}^{2}$ is equivalent to the weight loss of $22 \mathrm{~kg}$ for a woman with the weight of $80.5 \mathrm{~kg}$ and the height $158 \mathrm{~cm}$. This means that it changes the dose of doxorubicin $\left(50 \mathrm{mg} / \mathrm{m}^{2}\right)$ from $93.5 \mathrm{mg}$ to $80 \mathrm{mg}$.

Drugs pharmacokinetics (PK) does not largely explain the variability of the BSA. Patients' metabolism and the elimination of drugs vary. The same 
chemotherapy dose among patients can give different effects. The body surface area does not take into account the pharmacokinetic processes caused by cytotoxic drugs. The given mathematical analysis of the weight is proportional to (correlate) the volume. This assumption is a valid argument for investigation.

\section{METHODS}

The study involved 202 patients, including 164 (81.2\%) oncologic patients and $38(18.8 \%)$ control group patients. In the oncologic patient group there were $93(93.9 \%)$ men and $71(68.9 \%)$ women. The control group consisted of 6 (6.1\%) men and 32 (31.1\%) women. After the Pearson's chi-square test of men and women groups statistically differed significantly $(\chi 2=20.670, \mathrm{p}<0.001)$. Also, the Fisher's exact test shows that the null hypothesis probability is less than 0.001 .

Anthropometry: Body anthropometric parameters in cancer patients were used as scales, measuring tapes, antropometers (gauge height) and calliper. The body volume was determined from the formulas using anthropometric measurement data.

Adipose tissue (passive) mass of the formula:

$D=1,3 \times \frac{100+W+(H-160}{100} \times \frac{\left(d_{1}+d_{2}+d_{3}+d_{4}+d_{5}+d_{6}\right)}{12}$, where D - fat mass (kg), W - body weight $(\mathrm{kg}), \mathrm{H}$ - height $(\mathrm{cm}), \mathrm{d}$ - fat fold thickness $(\mathrm{mm})$ on the upper arm, forearm, thigh, lower leg, pass the ribs and abdomen.

Active muscle mass of the formula:

$M=6,5 \times H \times\left(\frac{E_{4 a p k}}{25,12}-\frac{E_{\text {Staukaudukrokas }}}{100}\right)^{2} \times 10^{-3}$, where $\mathrm{M}-$ muscle mass $(\mathrm{kg}) \mathrm{E} 4$ lower arm + forearm + Upper + Lower the amount of girth $(\mathrm{cm})$ E5 fat fold- 5 fold the amount of fat $(2 \times \mathrm{arm}+$ forearm + Upper + Lower $)(\mathrm{mm}), \mathrm{H}-$ height $(\mathrm{cm})$

Bone mass of: $O=1,2 \times H \times\left(\frac{E_{4 e p i}}{4}\right)^{2} \times 10^{-3}$, where $O$ - bone mass $(\mathrm{kg}), \mathrm{H}-$ height $(\mathrm{cm})$ E4epi - the distance between epicondil amount (arm epicondil + forearm + Upper + Lower $)(\mathrm{cm})$. Adipose tissue, muscle, bone mass determination in relative terms (\%) was carried out according to the formulas: 
Adipose tissue $\operatorname{mass}(\%)=\frac{\mathrm{D} \times 100}{\mathrm{~W}}$

Muscle mass $(\%)=\frac{M \times 100}{W}$

Bone mass $(\%)=\frac{\mathrm{O} \times 100}{\mathrm{~W}}$, where $\mathrm{W}-$ body weight $(\mathrm{kg})$

Mediumbuild body tissue composition in relative terms (\%):

\begin{tabular}{|l|c|c|c|}
\hline Gender & Adipose tissue mass & Muscle mass & Bone mass \\
\hline Male & $12.63-16.29$ & $32.91-35.18$ & $10.77-12.88$ \\
\hline Female & $19.60-24.21$ & $23.69-25.64$ & $8.64-9.61$ \\
\hline
\end{tabular}

Different cultures and different times have different body compositions, and a body composition is also associated with health and sports performances. The body fat is epidemiologically sensitive to gender and age. [18] There are different recommendations for the ideal body fat percentage. It is designed by the American Council (not an official government agency) recommendations. (Table 1)

Table 1. Aproximate relative amount of fat in the body of an adult.

\begin{tabular}{lcc}
\hline Description & Female & Male \\
\hline Essential fat & $8-12 \%$ & $3-5 \%$ \\
\hline Athletes & $14-20 \%$ & $6-13 \%$ \\
\hline Fitness & $21-24 \%$ & $14-17 \%$ \\
\hline "Average" & $25-32 \%$ & $18-24 \%$ \\
\hline Excess fat & $32 \%+$ & $25 \%+$ \\
\hline
\end{tabular}

Five formulas were used for calculating the BSA, ranked according to the RMSE Method of Prediction by Wang et al. (Table 2)

Table 2.

\begin{tabular}{ll}
\hline Autors & BSA $(\mathrm{KVL})$ formula \\
\hline Boydi & BSA $\left(\mathrm{m}^{2}\right)=\mathrm{Wt}(\mathrm{kg})^{0.4838 *} \mathrm{Ht}(\mathrm{cm})^{0.3 *} 0.017827$ \\
\hline Gehan and George & $\mathrm{BSA}\left(\mathrm{m}^{2}\right)=\mathrm{Wt}(\mathrm{kg})^{0.51456 *} \mathrm{Ht}(\mathrm{cm})^{0.42246 *} 0.02350$ \\
\hline Mosteller & $\mathrm{BSA}\left(\mathrm{m}^{2}\right)=\left[\mathrm{Ht}(\mathrm{cm})^{*} \mathrm{Wt}(\mathrm{kg}) / 3600\right)^{1 / 2}$ vai \\
& $\mathrm{BSA}\left(\mathrm{m}^{2}\right)=\left[\mathrm{Ht}(\mathrm{in})^{*} \mathrm{Wt}(\mathrm{lbs}) / 3131\right]^{1 / 2}$ \\
\hline Haycock & $\mathrm{BSA}\left(\mathrm{m}^{2}\right)=\mathrm{Wt}(\mathrm{kg})^{0.5378 *} \mathrm{Ht}(\mathrm{cm})^{0.3964 *} 0.024265$ \\
\hline Du Bois and Du Bois & $\mathrm{BSA}\left(\mathrm{m}^{2}\right)=\mathrm{Wt}(\mathrm{kg})^{0.425 *} \mathrm{Ht}(\mathrm{cm})^{0.725 *} 0.007184$ \\
\hline
\end{tabular}


The Body volume was determined from the formulas using anthropometric measurement data.

Statistical analysis: The study of statistical data analysis uses mathematical statistical methods to evaluate the measurements (length, thickness, circumference and weight), the reliability and the relevance of the theoretical probability distributions, as well as to check the set of statistical hypotheses. So the work has very widely used common (popular) methods of descriptive statistics, which are described in many books, such as the books on statistics of biology and medicine $[1,15,16]$. The variables are measured on a relative scale and were normally distributed (Gaussian obeyed the law), were analyzed using parametric statistical methods. In other cases, the use of parametric statistical methods was done. Hypotheses on the data with a normal probability of distribution is mainly tested in the Kolmogorov-Smirnovs test. Two-sample equal the arithmetical mean, using t-test. Three or more teams equal the arithmetical mean, for testing the analysis of variance (ANOVA) was used. ANOVA English - Analysis of variance. A number of cases was used to compare the chisquare test and the Fisher's exact test. Relationship among different variables for the analysis and the prediction of events were calculated by using correlation and linear regression methods. Statistical data processing of a database to MS Excel, then conversion of the data to the professional study of statistical data processing (analysis) program SPSS (Statistical Package for Social Sciences) version 16.0 for Windows followed. All the hypothesis tests used the duplex (2-tailed) of statistical hypotheses and the null hypothesis was rejected if the probability (of relevance, significance level) was less than $5 \%$ or $\mathrm{p}<0.05$.

\section{RESULTS}

Body Weight: In the study it was important to determine the sample descriptive statistic indicators. The average weight of 99 men was $78.5 \pm 16.4 \mathrm{~kg}$ and the mean body weight of 103 women was $70.1 \pm 14.6 \mathrm{~kg}$. After the Lieven test sample distribution was statistically significantly different $(\mathrm{F}=0.358, \mathrm{p}=0.551)$, but the independent-sample $\mathrm{t}$-test arithmetical means differed statistically significantly $(\mathrm{t}=3.839, \mathrm{p}<0.001)$. The men's average body weight was 59.9 passive $\pm 7.9 \mathrm{~kg}$ and the women's average body mass was passive $46.6 \pm 4.7 \mathrm{~kg}$. After the Lieven test sample distribution statistically 
differed significantly $(\mathrm{F}=18.003, \mathrm{p}<0.001)$ and independent samples t-test arithmetical means statistically differed significantly $(\mathrm{t}=14.512, \mathrm{p}<0.001)$. The men's ideal average body weight was $70.9 \pm 6.3 \mathrm{~kg}$ and the women's average body mass of the passive was $55.9 \pm 5.9 \mathrm{~kg}$. After the Lieven test sample distribution was statistically significantly different $(\mathrm{F}=1.123, \mathrm{p}=0.290)$, but the independent-sample $t$-test arithmetical means differed statistically significantly $(\mathrm{t}=17.434, \mathrm{p}<0.001)$.

Patient's height: Patient's height (body length standing) ranged from 148.6 to $192.5 \mathrm{~cm}$, the average height $-169.6 \pm 8.9 \mathrm{~cm}$. Patient's distribution according to height histograms and normal (Gaussian) distribution curve, where the average male's height was $175.5 \pm 6.9 \mathrm{~cm}$ and the females average height was $163.9 \pm 6.6 \mathrm{~cm}$ (Figure 1). After the Lieven test sample distribution was statistically significantly different $(\mathrm{F}=1.123, \mathrm{p}=0.290)$, but the independent-sample $t$-test arithmetic means differed statistically significantly $(\mathrm{t}=12.203, \mathrm{p}<0.001)$.

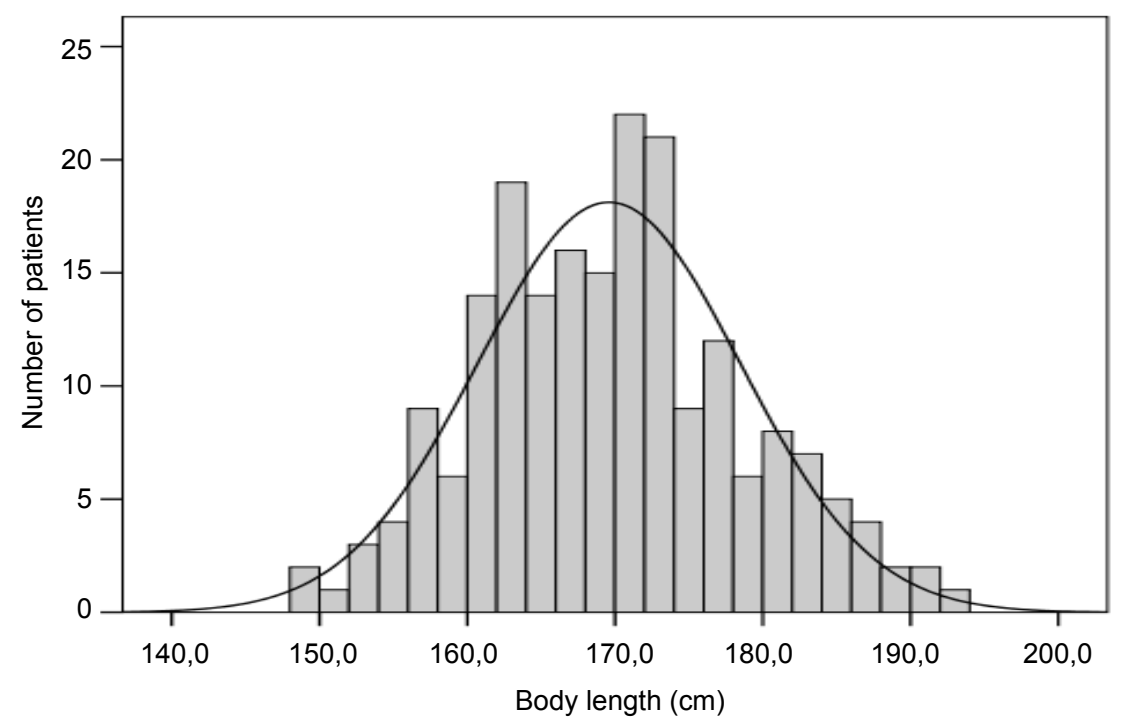

Figure 1. Patients with the absolute height distribution of the histogram and the normal (Gaussian) distribution curve.

Body Mass Index: The men's average body mass index was $25.41 \pm$ $4.73 \mathrm{~kg} / \mathrm{m}^{2}$ and the women's average body mass index was $26.20 \pm 5.90 \mathrm{~kg} / \mathrm{m}^{2}$. After the Lieven test sample distribution was statistically significantly different 
$(\mathrm{F}=3.075, \mathrm{p}=0.081)$, and also by independent samples $\mathrm{t}$-test arithmetical means was statistically significantly different $(t=1.043, \mathrm{p}=0.298)$.

Table 3. Oncologic patients in the absolute and relative distribution of groups according to body mass index.

\begin{tabular}{lccc}
\hline BMI group & Number & $\%$ & Accrued $\%$ \\
\hline Light & 23 & 11.4 & 11.4 \\
\hline Ideal weight & 98 & 48.5 & 59.9 \\
\hline A little too heavy & 17 & 8.4 & 68.3 \\
\hline Heavier & 33 & 16.3 & 84.7 \\
\hline Obesity & 31 & 15.3 & 100.0 \\
\hline Together & 202 & 100.0 & \\
\hline
\end{tabular}

Oncologic patients in the absolute and relative distribution of groups according to the body mass index in relation to the patient's gender (Table 4). After the Pearson's chi-square test of oncological patients in the absolute and relative distribution of groups according to body mass index in relation to the patient' gender differed statistically significantly $\left(\chi^{2}=11.510, \mathrm{df}=4, \mathrm{p}=0.021\right)$. We can see that about half of men have the ideal weight (body mass), but only about $1 / 3$ of women are with the ideal body weight.

Table 4. Oncologic patients in the absolute and relative distribution of groups according to the body mass index in relation to the patient's gender.

\begin{tabular}{lccccccc}
\hline \multirow{2}{*}{ BMI group } & \multicolumn{4}{c}{ Gender } & \multicolumn{2}{c}{ Together } \\
\cline { 2 - 6 } & \multicolumn{2}{c}{ Male } & \multicolumn{2}{c}{ Female } & & \\
\cline { 2 - 6 } & Number & $\%$ & Number & $\%$ & Number & $\%$ \\
\hline Light & 15 & 16.10 & 4 & 5.60 & 19 & 11.60 \\
\hline Ideal weight & 44 & 47.30 & 25 & 35.20 & 69 & 42.10 \\
\hline A little too heavy & 5 & 5.40 & 10 & 14.10 & 15 & 9.10 \\
\hline Heavier & 17 & 18.30 & 15 & 21.10 & 32 & 19.50 \\
\hline Obesity & 12 & 12.90 & 17 & 23.90 & 29 & 17.70 \\
\hline Together & 93 & 100.00 & 71 & 100.00 & 164 & 100.00 \\
\hline
\end{tabular}

Body surface area (BSA): The body surface area was used to calculate the methods described in five most popular formulas. The body surface area in the descriptive statistics is summarized (Table 5). The body surface area of the arithmetical mean and the standard deviations schedule of different methods of calculating the area are shown in Figure 2. 
Table 5. Descriptive statistics of the body surface area calculation formula.

\begin{tabular}{lcccc}
\hline BSA $^{2}$ & M & N & SD & m \\
\hline Mosteller & 1.88 & 164 & 0.22 & 0.01760 \\
\hline Du Bois \& Du Bois & 1.86 & 164 & 0.21 & 0.01618 \\
\hline Gehan and George & 1.90 & 164 & 0.23 & 0.01787 \\
\hline Boyd & 1.91 & 164 & 0.24 & 0.01839 \\
\hline Haycock & 1.90 & 164 & 0.24 & 0.01848 \\
\hline
\end{tabular}

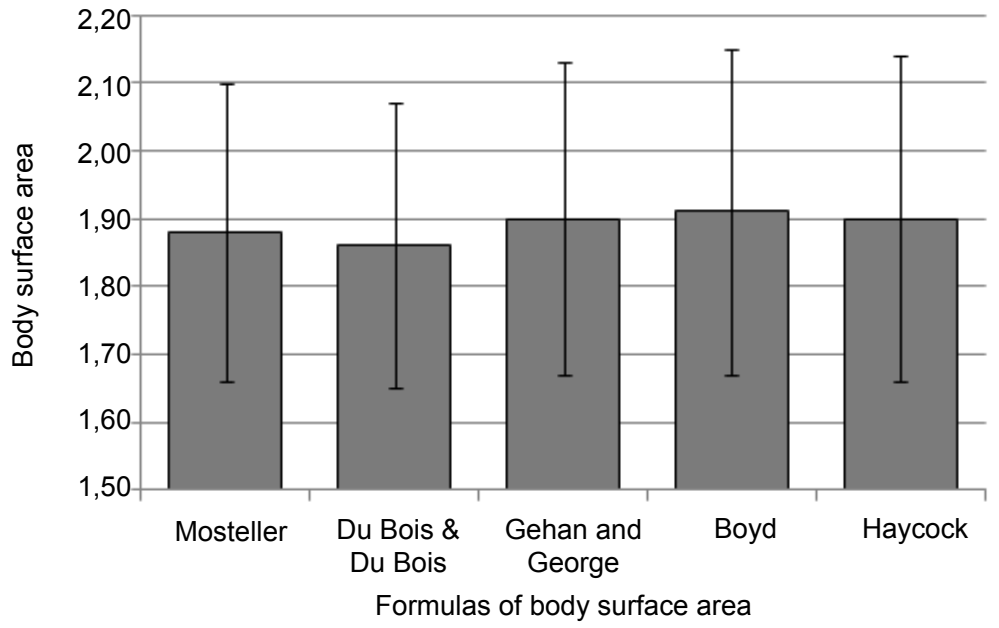

Figure 2. Body surface area of the arithmetical mean and the standard deviations schedule of different methods of the calculating area.

The relative comparison of different calculation methods for the body surface are given in relation to the patient's gender (Table 6). After using a variety of arithmetic formulas in the calculation of the BSA men's differs less than $1 \%$ compared to the calculated area of the Mosteller formula. For women the difference is more than $1 \%$.

Among the body surface areas, calculated using different formulas there is a positive, strong and statistically significant $(\mathrm{p}<0.001)$ correlation. Calculated after Mosteller and Boyd formulas the body surface area of interrelationships between the points in the chart with gender (Figure 3). 
Table 6. Body surface area, relative comparison of different calculation methods in relation to the patient's gender.

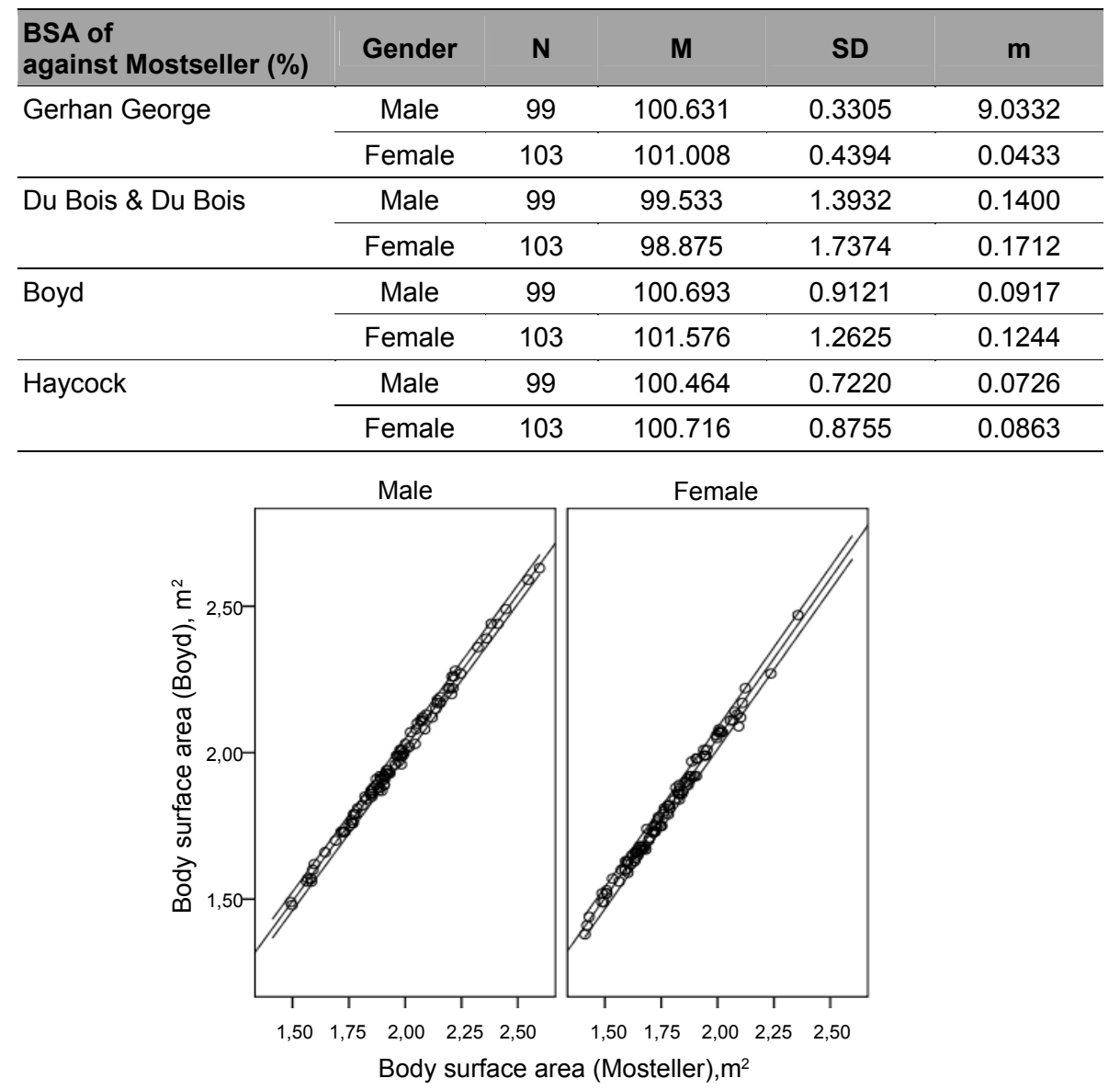

Figure 3. Calculated after Mosteller and Boyd formulas the body surface area of the interrelationships between points graphs, the linear regression lines and their $95 \%$ confidencial interval limits in relation to the patient's gender.

Among the various calculated body surface areas there is a linear relationship (coefficient of determination $r^{2}=0.991$ ). Since the analysis of variance (ANOVA) significance level areas interconnecting the $\mathrm{p}<0.001$, then these fields are obtained using a linear combination. When the linear regression analysis was used, the equations, obtained by linear regression are:

Male:

BSA $($ Boyd $), \mathrm{m}^{2}=-0,078+1,047 \times$ BSA $($ Mosteller $), \mathrm{m}^{2}$;

Female:

BSA $($ Boyd $), \mathrm{m}^{2}=-0,130+1,090 \times$ BSA $($ Mosteller $), \mathrm{m}^{2}$. 
Body fat: The body fat calculation, using the body mass index, being put into practice by Deurenberg [3]. Correlations between densitometric body fat percentage (BF\%) and BMI considering age and gender. Children and adults, body fat percentage calculated from different formulas:

$$
\begin{gathered}
\text { Body fat }(\text { for children }) \\
\%=(\mathbf{1 . 5 1} \times \mathbf{B M I})-(\mathbf{0 . 7 0} \times \text { age })-(3.6 \times \text { Gender })+\mathbf{1 . 4} ; \\
\text { Body fat }(\text { for adults }) \\
\%=(\mathbf{1 . 2 0} \times \mathbf{B M I})+(\mathbf{0 . 2 3} \times \text { age })-(\mathbf{1 0 . 8} \times \text { Gender })-\mathbf{5 . 4}, \\
* \text { Gender }=1(\text { for Male }) \\
\text { Gender }=0(\text { for Female })
\end{gathered}
$$

The average body fat of oncologic patient's percentage for men was $27.3 \pm 7.2 \%$ and $31.1 \pm 9.7 \%$. After the independent samples the $t$-test two sample arithmetical means differed statistically significantly $(t=8.105$ and $\mathrm{p}<0.001)$. The distribution of patients in groups [18], the body fat content $(\%)$ of the patient shows that male and the female patients were primarily from the group with excessive fat in the body, the body fat for men is $25 \%$ or more of the total body weight, but that of women is over $32 \%$ of the total body weight. Calculated after the Mosteller formula the body surface area and the body fat interrelationships point graphically, the regression lines and their $95 \%$ confidencial interval limits in relation to the patients' gender appear (Figure 4). The correlation analysis showed that the body fat for men correlates with the body surface area, calculated using the Mosteller formula $(\mathrm{r}=0.663, \mathrm{p}<0.001)$ and the fat content for women correlates with the body surface area, calculated using the Mosteller formula $(\mathrm{r}=0.760, \mathrm{p}<0.001)$. We can see that outside the $95 \%$ confidencial interval limits for men are 5 cases, but for women there are only 2 cases.

The body volume: The body volume study enrolled the patients ranged from 37.3 to $124.6 \mathrm{dm}^{3}$ (liters). The oncologic patients body volume ranged from 40.3 to $124.6 \mathrm{dm}^{3}$ (liters). The body volume mean value was $72.2 \pm 16.7 \mathrm{dm}^{3}$. For all the men involved in the study the body volume the mean value was $74.7 \pm 16.7 \mathrm{dm}^{3}$, the mean value of the female body volume was $66.2 \pm$ $14.9 \mathrm{dm}^{3}$. After the independent samples t-test between men and women in the body volume, the arithmetical means differed statistically significantly $(t=3.839, p<0.001)$. For the male body volume the mean value was $75.0 \pm$ 
$17.1 \mathrm{dm}^{3}$, for the female body volume the mean value was $68.6 \pm 15.6 \mathrm{dm}^{3}$. After the independent samples t-test between men and women in the body volume, the arithmetical means differed statistically significantly $(t=2.437$, $\mathrm{p}=0.016)$ (Figure 5).

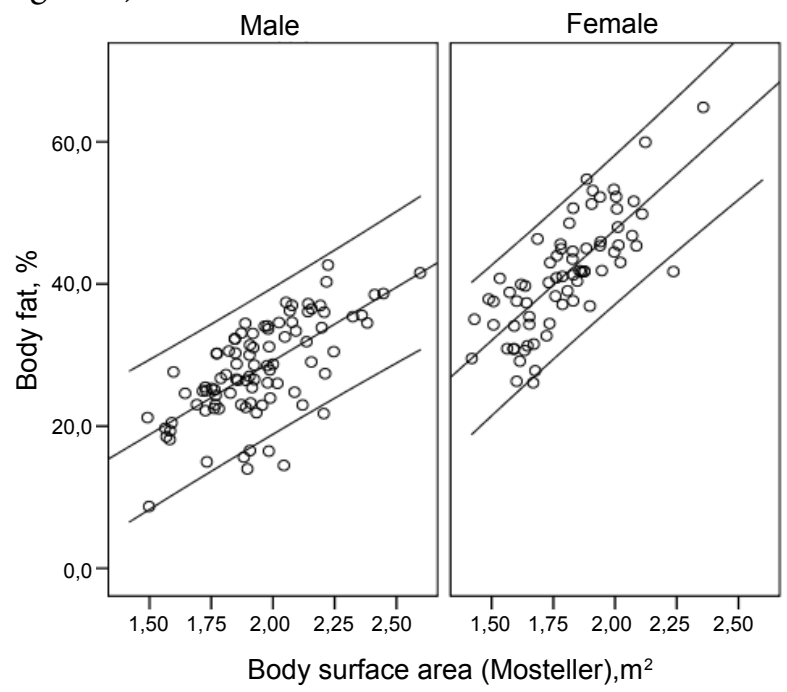

Figure 4. Calculated after the Mosteller formula the body surface area and the body fat interrelationships point graphs, the regression lines and their $95 \%$ confidencial interval limits in relation to the patients' gender.

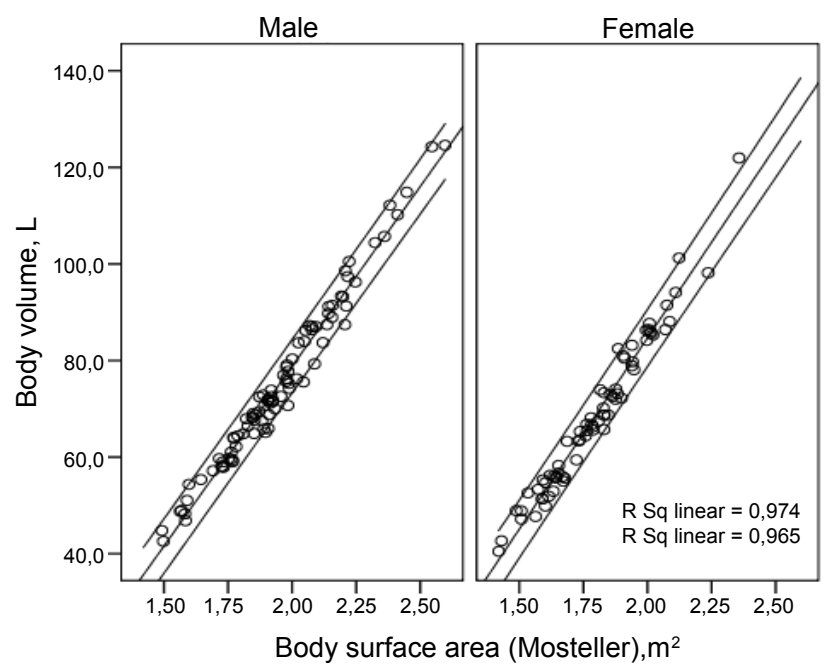

Figure 5. Calculated after the Mostsellera formula the body surface area and the body volume (in liters) and between points graphs, the linear regression lines and their $95 \%$ confidencial interval limits in relation to the patients' gender. 


\section{DISCUSSION}

Anthropometric measurements are suitable for the calculation of the doses of chemotherapy, but taking into account the correlation it cannot be excluded that they reflect the same body surface area. The BMI does not feature the percentage of the fat mass of the whole body. Consequently, it is possible that the patient's body density is a more physiological parameter, which could be determined for comparison by using abdominal computer tomography. The body volume index (BVI) could be one of the most recent parameters for the more accurate calculation of chemotherapy for cancer patients. The Body Volume Index (BVI) is a new measurement for human obesity that has been proposed as an alternative to the Body Mass Index (BMI). The BMI is based on a measurement of the total mass, irrespective of the location of the mass, but the BVI looks at the relationship between mass and volume distribution (i.e. where the body mass is located on the body). Recent studies have highlighted the limitations of the BMI as an indicator of the individual health risk $[19,20]$. The Body Volume Index (BVI) was originally devised in February 2000 as a new modern day measurement for measuring obesity; an alternative to the Body Mass Index (BMI) which was originally conceived between 1830 and 1850. The BMI is based on height and weight only, but the new BVI system automatically measures the BMI, waist circumference and waist-hip ratio in addition to the highly sophisticated volumetric and body composition analysis. It is projected that scientific and technical development of the BVI may take a similar period to the BMI, so the year 2020 is the current projected date for adoption and delivery on the scale required. By 2012 there were 6 scientific and 7 academic institutions involved in the evaluation and validation of the BVI as a potential new health risk measurement and indicator, which has been ongoing since March 2007. The BVI is an application [21] that can be used on a 3D Full Body Scanner to determine the individual health risk, whether the scanning hardware uses visible light optical information or otherwise. The BVI allows the differentiation between the people who are assigned the same BMI rating, but who have a different body shape and weight distribution, so that their individual BMI rating may not accurately reflect their own risk. The BVI has undergone clinical trials in the U.S. and Europe as part of a three year collaborative project, the Body Benchmark Study, the results of which were presented in October 2010 at a publicaly funded launch in Birmingham, the UK and scientific research and evaluation continuied in 2011 [22,23]. Whereas the BMI of a person is measured manually by total weight and height, the BVI 
is calculated by using 3D full body data to determine volume or weight distribution. The BVI measures where the weight and the fat are distributed on a person's body, rather than the total weight or the total fat content. There has been an acceptance in recent years that abdominal fat and weight around the abdomen constitute a greater health risk[24], commonly known as central obesity. A full body surface scanner determines the three-dimensional outline of a person's exterior surface, so that computation can be used to calculate the part volumes and the part body composition of that person. The BVI makes an inference as to the body's distribution of weight and the distribution of muscle and fat, using complex and detailed Body Composition data[25]. Most 3D scanners suitable for the BVI require that the subject is scanned for a series of images under varying lighting conditions (various projected patterns), to determine the body shape and weight distribution data for the individual patient and the statistical analysis and the BVI is currently under evaluation by government agencies in the UK as a possible long-term replacement for the BMI. The BVI was conceived as a potential replacement for the BMI at the turn of the millennium and after preliminary development, initial validation was undertaken by the Heartlands Hospital, a NHS Obesity Centre in the UK. This was followed by clinical testing in the US by the Mayo Clinic in Rochester, Minnesota[26]. An initial pilot study highlighted the potential of the BVI as a motivational tool for the weight loss in patients and as part of the Body Benchmark Study, a recent further study aimed to assess the validity and reproductibility of the BVI scanner in measuring the anthropometric markers of obesity[22,27]. Comparative validation of the reliability of automatic measurement as opposed to manual measurement concluded that the scanner is a reliable, valid and reproducible method to measure waist and hip circumferences[27]. Ongoing developments in 2012 include initial benchmarking of the BVI values for children aged 4-17 and the collation of 3D data in the US and Europe for use as normative data for the BVI in male and female adults.

\section{REFERENCES}

1. Altman D.G. (1999). Practical Statistics for Medical Research. London, Chapman \& Hall, 1999, pp. 611.

2. Banerjee S., Sen R. (1955). Determination of the surface area of the body of Indians. J Appl Physiol, 7, 585-588. 
3. Deurenberg P., Weststrate J.A., Seidell J. C. (2007). Body mass index as a measure of body fatness: Age- and sex-specific prediction formulas. British Journal of Nutrition, 65, 2, 105-14.

4. Du Bois D., Du Bois E. F. (1916) A formula to estimate the approximate surface area if height and weight be known. Archives of Internal Medicine. 17, 863-871.

5. Fahey T., Insel P., Roth W. (2010). Body Composition. Fit \& Well, Core Concepts and Labs in Physical Fitness and Wellness, McGraw-Hill.

6. Favier M., de Cazanove F., Saint-Martin F., Bressolle F. (1994). Preventing medication erros in antineoplastic therapy. American Journal of Hospital Pharmacy 51, 832-833.

7. Gehan E. A., George S. L. (1970). Estimation of human body surface area from height and weight. Cancer Chemother Rep 54, 225-235.

8. Gurney H. (2006). Developing a New Framework for Dose Calculation. Journal of Clinical Oncology, 24, 10, 1489-1490.

9. Jackson A. S., Stanforth P. R., Gagnon J., Rankinen T., Leon A. S., Rao D. C., Skinner J. S., Bouchard C. et al. (2002). True. International Journal of Obesity, 26, 6, 789-96.

10. Jones P. R. M., Wilkinson S., Davies P. S. W. (1985). A revision of body surface area estimations. European Journal of Applied Physiology, 53, 376-379.

11. Mathematical Sciences Education Board. High School Mathematics at Work: Essay and Examples for the Education of All Students, 145-146, 1998.

12. Mosteller R. D. (1987). Simplified calculation of body-surface area. New England Journal of Medicine, 317, 1098.

13. Polovich M., White J.M., Kelleher L. (2005). Chemotherapy and biotherapy guidelines and recommendations for practice ( $2^{\text {nd }}$ ed.). Pittsburgh, PA: Oncology Nursing Society

14. Rogers J. A., Blake-James M., Green S. (2002). Investigation into the relationship between body surface area and Kopā body potassium using Monte Carlo and measurement. Physics in Medicine and Biology, 47, 5, 789-800.

15. Teibe U. (2007). Biolog̣iskā statistika. Rīga, LU Akadēmiskais apgāds, 156 lpp.

16. Teibe U., Berķis U. (2001). Varbūtību teorijas un matemātiskās statistikas elementi medicinas studentiem. Rīga, AML/RSU, 88 lpp.

17. Anjana M., Sandeep S., Mphil R., Vimaleswaran K. S., Farooq S., Mohan V. (2004). Visceral and Central Abdominal Fat and Anthropometry in Relation to Diabetes in Asian Indians. Diabetes care, 27, 12, 2948-2953.

18. Carey D. G. P. (1998). Abdominal Obesity. Current Opinion in Lipidology. 9, 1. Retrieved on April 9, 2012, 35-40.

19. Romero-Corral A., Somers V. K., Sierra-Johnson J., Thomas R. J., Collazo-Clavell M. L., Korinek J., Allison T. G., Batsis J. A., Sert-Kuniyoshi F. H., LopezJimenez F. (2008). Accuracy of body mass index in diagnosing obesity in the adult general population. International Journal of Obesity 32 (6), 959-956. 
20. Association of bodyweight with total mortality and with cardiovascular events in coronary artery disease: a systematic review of cohort studies. Lancet (2006-0819) 368(9536): 666-78. (Retrieved on 2008-09-08).

21. Bespoke software used in the Body Volume Index (BVI) 3D Body Scanner [1] a b [2]

22. Barnes R., Rahim A. (2009). The Body Volume Index: New Imaging Technology for Body measurement. Hospital Imaging \& Radiology Europe Autumn 2009, 4, (Retrieved on 2010-29-02).

23. Craver R. (2008). Location, not volume, of fat found to be key www.journalnow.com. Retrieved on 2008-10-09.

24. Abd T., Boelaert K., Barnes R., Palin S., Field A., Redmayne H., Aytok L., Rahim A. (2008). Body volume index: time to replace body mass index?. Endocrine Abstracts (Society for Endocrinology, British Endocrine Societies) 15, 104. http://www.endocrine-abstracts.org/ea/0015/ea0015pl104.htm. Retrieved 2008-09-07.

25. Romero-Corral A., Somers V., Lopez-Jimenez F., Korenfeld Y., Palin S., Boelaert K., Boarin S., Sierra-Johnson J., Rahim A. (2008). 3-D Body Scanner, Body Volume Index: A Novel, Reproducible and Automated Anthropometric Tool Associated with Cardiometabolic Biomarkers Obesity A Research Journal 16 (1), 266-P.

26. Boelaert K., Palin S., Field A., Rahim A., Barnes R. http://www.endocrineabstracts.org/ea/0015/ea0015p125.htm.

27. Korenfeld Y., Ngwa T., Friedman L., Romero-Corral A., Somers V., Xu L. Albuquerque F., Sert-Kuniyoshi F., Ockay A., Lopez-Jimenez F. Validation of a Novel 3D Body Scanner for Obesity Anthropometric Measurements AHA.

\section{Address for correspondence:}

Aija Gerina-Berzina

Paul Stradins University Hospital

Clinic of Oncology

Pilsonu Street 13, LV-1002, Riga, Latvia

E-mail: a.gerina@inbox.lv 